\title{
Breast milk n-3 long-chain polyunsaturated fatty acids and blood pressure: an individual participant meta-analysis
}

\author{
Lenie van Rossem ${ }^{1,2}(1) \cdot$ Henriette A. Smit ${ }^{1} \cdot$ Martine Armand $^{3}$. Jonathan Y. Bernard ${ }^{4} \cdot$ Hans Bisgaard $^{5}$. \\ Klaus Bønnelykke ${ }^{5}$. Signe Bruun ${ }^{6,7,8,9} \cdot$ Barbara Heude $^{4}$. Steffen Husby ${ }^{7,8,9} \cdot$ Henriette B. Kyhl ${ }^{7,9}$. \\ Kim F. Michaelsen ${ }^{10} \cdot$ Ken D. Stark $^{11} \cdot$ Carel Thijs $^{12} \cdot$ Rebecca K. Vinding ${ }^{5}$ Alet H. Wijga ${ }^{13} \cdot$ Lotte Lauritzen $^{10}$
}

Received: 16 December 2019 / Accepted: 15 June 2020 / Published online: 20 June 2020

(c) The Author(s) 2020

\begin{abstract}
Purpose It is controversial whether a higher intake of n-3 long-chain polyunsaturated fatty acids (n-3 LC PUFA) through breastfeeding is associated or not to a lower blood pressure (BP) during childhood. We aimed to clarify this point by undertaking a meta-analysis involving the data from seven European birth cohorts.

Methods We searched https://www.birthcohort.net for studies that had collected breast milk samples, and had at least one BP measurement in childhood. Principal investigators were contacted, and all agreed to share data. One additional study was identified by contacts with the principal investigators. For each cohort, we analyzed the association of breast milk n-3 LC PUFAs with systolic and diastolic BP with linear mixed effects models or linear regression, and pooled the estimates with a random effects model. We also investigated age-specific and sex-specific associations.

Results A total of 2188 participants from 7 cohorts were included. Overall, no associations between breast milk n-3 LC PUFAs and BP were observed. In the pooled analysis, each $0.1 \mathrm{wt} \%$ increment in breast milk docosahexaenoic acid (DHA) was associated with a $1.19(95 \% \mathrm{CI}-3.31,0.94) \mathrm{mmHg}$ lower systolic BP. Associations were similar for boys and girls and at different ages.

Conclusion In this individual participant meta-analysis, we found no evidence for an association between breast milk n-3 LC PUFAs and BP.
\end{abstract}

Keywords Breastfeeding $\cdot$ Blood pressure $\cdot$ Fatty acids $\cdot$ Children

Electronic supplementary material The online version of this article (https://doi.org/10.1007/s00394-020-02310-4) contains supplementary material, which is available to authorized users.

Lenie van Rossem

1.vanrossem@umcutrecht.nl; 1.vanrossem@erasmusmc.nl

1 Julius Center for Health Sciences and Primary Care, University Medical Center Utrecht, Utrecht University, Universiteitsweg 100, 3584 GA Utrecht, The Netherlands

2 Department of Obstetrics and Gynaecology, Erasmus MC University Medical Center, Rotterdam, The Netherlands

3 Aix Marseille Univ, CNRS, CRMBM, Marseille, France

4 Université de Paris, Centre for Research in Epidemiology and StatisticS (CRESS), INSERM, INRA, 75004 Paris, France

5 COPSAC, Copenhagen Prospective Studies on Asthma in Childhood, Herlev and Gentofte Hospital, University of Copenhagen, Copenhagen, Denmark

6 Strategic Business Unit Pediatric, Arla Foods Ingredients Group P/S, Viby J, Denmark
7 Hans Christian Andersen Children's Hospital, Odense University Hospital, Odense, Denmark

8 Department of Clinical Research, Faculty of Health Sciences, University of Southern Denmark, Odense, Denmark

9 OPEN, Odense Patient Data Explorative Network, Odense University Hospital, Odense, Denmark

10 Department of Nutrition, Exercise and Sports, University of Copenhagen, Copenhagen, Denmark

11 Department of Kinesiology, Faculty of Applied Health Sciences, University of Waterloo, Waterloo, Canada

12 Department of Epidemiology, Care and Public Health Research Institute (CAPHRI), Maastricht University, Maastricht, The Netherlands

13 Center for Nutrition, Prevention, and Health Services, National Institute for Public Health and the Environment, Bilthoven, The Netherlands 


\section{Introduction}

Breastfeeding has established short term advantages for the infants such as fewer infections [1], but may benefit longer term health as well, especially on cardiovascular health. Indeed, three meta-analyses reported associations of breastfeeding as compared with infant formula with lower blood pressure (BP) in childhood and adulthood [2-4].

The composition of breast milk strongly differs from infant formula, among others as breastmilk contains n-3 long-chain polyunsaturated fatty acids (n-3 LCPUFAs), especially EPA (eicosapentaenoic acid) and DHA (docosahexaenoic acid), which traditionally were not present in infant formula [5]. The beneficial effect of breastfeeding as compared to infant formula on BP is suggested to be due to differences in n-3 LC PUFA, especially DHA. N-3 LC PUFAs are important for BP control, among others via incorporation in endothelial cells in blood vessels, effects on balance between sympatic and parasympatic signaling from the brain, and eicosanoid regulation of BP [6-8]. In addition, there is a competition in the biosynthesis of DHA and arachidonic acid (AA), a n-6 LCPUFA, as the same enzymes are involved in the conversion steps from their respective precursors alpha-linolenic acid (n-3 PUFA) or linoleic acid (n-6 PUFA) [9]. This potential mechanism could be especially important in early life, where exposure may permanently change the function and structure of organs [10]. In addition, DHA deficiency in the perinatal period has been shown to be associated with an alteration in BP control later in life in rats [11]. A simple comparison of breastfeeding with formula feeding can not fully elucidate the potential role of n-3 LC PUFAs, as the fatty acid composition of breast milk varies between mothers [12], due to maternal diet and metabolic status [13,14] and maternal genes [15].

Previous studies on the role of n-3 LC PUFAs in healthy infants born at term on BP later in life reported mixed findings, but the studies differ widely in methods of exposure and age of BP assessment in the children. One longitudinal cohort study observed that breast milk with a relatively high content of n-3 LC PUFA associated with a lower BP in children at 12 years of age when EPA and DHA levels were at or more than median values, i.e. $0.05 \%$ for EPA and $0.18 \%$ for DHA [16]. Randomized trials have examined effects of enriched infant formula $[17,18]$ or direct fish oil supplementation of infants [19] as well as n-3 LC PUFA supplementation of lactating mothers [20-23]. In the latter case, BP was not different at the age of 2.5 years, but BP was higher in boys at the age of 7 years and 13 years of age in those whose mothers received supplementation during lactation.

In the present study, we investigated the association between n-3 LC PUFAs in breast milk and long term BP with a meta-analysis using individual participant data (IPD) from seven birth cohort studies. Furthermore, we examine potential age-specific and sex-specific associations. Earlier studies suggested that DHA (22:6n-3) is the most important of the n-3 LC PUFAs regarding its effect on BP in adults [24, 25]; this was also observed in the previous study on breast milk fatty acids and BP [16]. Therefore, our primary interest was in DHA. We also assessed eicosapentaenoic acid (EPA, 20:5n-3) and considered the ratio of DHA/AA.

\section{Methods}

\section{Participating cohorts and design}

We performed an individual participant data (IPD) metaanalysis. Using the https://www.birthcohorts.net website, we identified six studies that had collected breast milk samples and had at least one measurement of BP during childhood. All six eligible birth cohorts (COPSAC2000 [26], COPSAC2010 [27], EDEN [28], KOALA [29], OCC [30], PIAMA [31]) agreed to participate. The principal investigators of the studies or their representatives were invited to share data on breast milk fatty acid composition, BP, and covariates of their study. Through the PIs of the earlier mentioned cohorts, one additional study (CU Trial) [32] was identified. This was an intervention study designed to supplement lactating mothers with fish oil, which assessed the resulting effect on breast milk fatty acid composition. The supplement in this trial provided $1.5 \mathrm{~g} /$ day of $\mathrm{n}-3$ LC PUFA, which resembled the upper range in the intake from dietary sources in the Danish population. Other studies were observational in nature, or with an intervention that was unrelated to this research question (e.g. mattress covers in PIAMA for prevention of allergies), with the exception of COPSAC2010. In this study, women were randomized to supplementation during the third trimester of pregnancy with either $2.4 \mathrm{~g}$ /day fish oil (55\% EPA and 37\% DHA) or olive oil. Thus, we included seven studies from Denmark, France, and the Netherlands representing a total of 2188 participants. All studies obtained ethical approval from local institutional review boards and have therefore been performed in accordance with the ethical standards laid down in the 1964 Declaration of Helsinki and its later amendments. The data for this meta-analysis were stored in a single center on a secured data server with access for the first author ( $\mathrm{v} v \mathrm{R})$ only.

\section{Breast milk fatty acid composition}

Gas chromatography with flame ionization was used to determine the fatty acid composition of all the milk samples, although there were some differences in sampling, 
preparation and fatty acid analysis (please see Supplemental Table 1 for details). In general, these methods can produce relatively similar results although the use of acid-based catalysts can result in higher fatty acid recoveries [33], although at an increased risk of degrading of conjugated linoleic acid (a fatty acid of interest in dairy products) [34]. Expressing the fatty acid data as a relative weight percentage (wt $\%$ ) of the total fatty acid content helps standardize fatty acid data [35], and we focused on DHA and EPA levels as well as DHA/AA ratio and not conjugated linoleic acid.

\section{BP measurements}

The outcomes of interest were Systolic blood pressure (SBP) and Diastolic blood pressure (DBP). All studies used an automated oscillatory device to measure BP. The specific devices of each cohort are listed in Supplementary Table 1 of Online resource 1 . Protocols were fairly similar, including a 5-10 min rest before measurements, an appropriately adjusted cuff size, measurement on the non-dominant or left arm, and a sitting or supine position. Furthermore, most studies (expect one) took several measurements which were averaged (with one study excluding the first measurement). We used BP in $\mathrm{mmHg}$ in the main analyses, adjusting for height, age, and sex in each analysis as BP in children is a function of length/height, age, and sex. In addition, for descriptive purposes, we show BP $z$-scores to be able to compare BP across ages. $z$-scores were derived from the Pediatric Hypertension Guidelines, updated from The Fourth Report on the Diagnosis, Evaluation, and Treatment of High BP in Children and Adolescents [36].

\section{Covariates}

All cohorts obtained information on covariates; most covariates were based on self-reported questionnaires and some covariates were derived from medical records. These covariates were maternal age (years), maternal educational level (low, medium, high), maternal place of birth (European, non-European), maternal pre-pregnancy body mass index (BMI) $\left(\mathrm{kg} / \mathrm{m}^{2}\right)$, smoking status during pregnancy (yes, no), infant's birth weight (grams), and gestational age (weeks) as the main potential confounders in the statistical analysis. All covariates were included a priori in the model, because of their known association with blood pressure.

\section{Statistical analysis}

For each study, we describe the mean (SD) of breast milk fatty acid levels ( $\mathrm{wt} \%$ ) and $\mathrm{BP}$ (mmHg and $z$-scores).

As the included studies measured BP at different ages, we assumed that statistical heterogeneity was present. Therefore, we applied a random effects meta-analysis which estimates the average association between the determinant and the outcome [37, 38]. We performed a two-stage metaanalysis. In the first stage, we ran two models for each study. Model 1 included the association between fatty acid level (DHA, EPA, or the DHA/AA ratio) and BP, adjusted for age, sex, and height. For this model, we fitted several models for height, by adding "height ${ }^{2 "}$ " and "height" to the model, and ran the model with the best fit for height, as determined by the $-2 \log$ likelihood. For most studies, height was used as a single term. Six out of the seven included studies had repeated measurements of BP. For these studies a mixed model was used, to account for the intra-cohort correlations between the measurements. For the study with the single outcome measurement (i.e. KOALA), we used a linear regression model. In addition to height, age and sex, model 2 was further adjusted for the above-mentioned potential confounders and breastfeeding duration. In the second stage, the estimates of each study were pooled with a mixed model, where each cohort was a random effect, and each cohort was assigned a weighting factor (1/variance). Estimates represent the difference in $\mathrm{BP}(\mathrm{mmHg})$ per $0.1 \mathrm{wt} \%$ increase in breast milk fatty acids levels, which would be a realistic increase given the range of fatty acids in the studies.

From studies in adults on the association between fatty acids and BP, it has been suggested that the association may not show a dose-response relationship [39]. Therefore, we also examined associations with BP with breast milk DHA dichotomized at the median for each study.

We examined the interactions between breast milk and child sex and age in relation with BP by adding the appropriate interaction terms (e.g. DHA $\times$ sex) into the models.

As child's height and child's BMI could be an intermediate or modifying factor in the association between DHA and $\mathrm{BP}$, given evidence in the literature on an association between DHA and height $[40,41]$ and DHA and BP in overweight children [42], we performed a sensitivity analysis where we used height and BMI as the outcome instead of BP. For those studies that had an intervention component by design (related or unrelated), we checked whether the associations were similar for the intervention and control arms.

Data analysis was conducted with SAS software version 9.4 (SAS Institute, Inc., Cary, NC, USA).

\section{Results}

Almost all participants (96.7\%) had a European background. Mean (SD) maternal pre-pregnancy BMI was 23.2 (4.1) kg/ $\mathrm{m}^{2} ; 26.8 \%$ were overweight or obese. Smoking occurred in $11.4 \%$ of pregnancies. Mean birth weight of the infants was 3470 (515) g, and mean gestational age was 39.7 (1.6) weeks (Table 1$)$. The percentages boys and girls ( $50 \%)$ and 
Table 1 Characteristics of the studies, and total and cohort-specific descriptive statistics of the study participants

\begin{tabular}{|c|c|c|c|c|c|c|c|c|}
\hline Covariates & Total & COPSAC2000 & COPSAC2010 & CU Trial & EDEN & KOALA & OCC & PIAMA \\
\hline \multicolumn{9}{|l|}{ Study characteristics } \\
\hline$N^{\mathrm{a}}$ & 2188 & 278 & 532 & 127 & 721 & 75 & 308 & 147 \\
\hline Year of recruitment & - & 2000 & 2010 & 1998-1999 & 2003-2006 & $2000-2002$ & 2010-2012 & 1996-1997 \\
\hline $\begin{array}{l}\text { Age at outcome measure- } \\
\text { ment, in years }\end{array}$ & - & $12 ; 18$ & $3 ; 6 ; 8$ & $2.5 ; 7 ; 13$ & $3 ; 5$ & 6 & $0.4 ; 1.5 ; 3 ; 5$ & $12 ; 16$ \\
\hline \multicolumn{9}{|l|}{ Maternal characteristics } \\
\hline $\begin{array}{l}\text { Age at child's birth, in years } \\
\text { (mean, SD) }\end{array}$ & $30.9(4.4)$ & $30.2(4.5)$ & $32.6(4.3)$ & $30.9(3.8)$ & $30.0(4.7)$ & $33.2(3.6)$ & $30.6(4.1)$ & $31.2(3.5)$ \\
\hline Low educational level $(\%, n)$ & $12.8(273)$ & $39.2(109)$ & $2.3(12)$ & $2.4(3)$ & $16.7(120)$ & $4.0(3)$ & $4.4(11)$ & $10.2(15)$ \\
\hline $\begin{array}{l}\text { Non-European place of birth } \\
(\%, n)\end{array}$ & $3.3(65)$ & $2.9(8)$ & $4.0(21)$ & n.a & $3.5(25)$ & $1.4(1)$ & $2.4(6)$ & $3.5(5)$ \\
\hline BMI, in $\mathrm{kg} / \mathrm{m}^{2}$ (mean, SD) & $23.2(4.1)$ & n.a & $24.1(4.4)$ & $22.5(2.7)$ & $22.9(4.4)$ & $23.5(3.3)$ & $24.0(4.3)$ & $22.4(2.9)$ \\
\hline $\begin{array}{l}\text { Overweight status } \\
\text { Underweight } \\
\text { Normal weight } \\
\text { Overweight } \\
\text { Obese }\end{array}$ & $\begin{array}{l}6.2(64) \\
69.0(1047) \\
18.0(273) \\
6.8(103)\end{array}$ & $\begin{array}{l}\text { n.a } \\
\text { n.a } \\
\text { n.a } \\
\text { n.a }\end{array}$ & $\begin{array}{l}1.9(3) \\
68.4(108) \\
20.9(33) \\
8.9(14)\end{array}$ & $\begin{array}{l}4.7(6) \\
78.7(100) \\
16.5(21) \\
0(0)\end{array}$ & $\begin{array}{l}9.4(67) \\
67.8(483) \\
15.3(109) \\
7.4(53)\end{array}$ & $\begin{array}{l}2.7(2) \\
69.3(52) \\
22.7(17) \\
5.3(4)\end{array}$ & $\begin{array}{l}3.9(12) \\
62.5(192) \\
24.1(74) \\
9.5(29)\end{array}$ & $\begin{array}{l}2.9(4) \\
81.2(112) \\
13.8(19) \\
2.2(3)\end{array}$ \\
\hline Smoking $(\%, n)$ & $11.4(241)$ & $23.0(64)$ & $4.9(26)$ & $1.8(2)$ & $19.6(139)$ & $0.0(0)$ & $0.3(1)$ & $7.5(11)$ \\
\hline $\begin{array}{l}\text { Gestational age, in weeks } \\
\text { (mean, SD) }\end{array}$ & $39.7(1.6)$ & $40.0(1.5)$ & $39.9(1.6)$ & $40.1(1.1)$ & $39.3(1.6)$ & $39.6(1.2)$ & $39.7(1.4)$ & $40.2(1.3)$ \\
\hline \multicolumn{9}{|l|}{ Child characteristics } \\
\hline $\begin{array}{l}\text { Infant's birth weight, in } \\
\text { grams (mean, SD) }\end{array}$ & $3470(515)$ & $3557(507)$ & $3560(530)$ & $3595(448)$ & $3291(498)$ & $3593(462)$ & $3571(496)$ & $3543(490)$ \\
\hline Infant's sex $(\%, n)$ boys & $50.5(1076)$ & $50.7(141)$ & $49.4(263)$ & $43.3(55)$ & $49.7(358)$ & $51.4(38)$ & $51.3(158)$ & $48.3(7.1)$ \\
\hline $\begin{array}{l}\text { Breastfeeding duration, in } \\
\text { weeks (mean, SD) }\end{array}$ & $31.5(19.3)$ & $37.9(21.2)$ & $37.5(19.0)$ & $37.5(14.9)$ & $19.5(15.0)$ & $30.6(14.9)$ & $44.5(16.6)$ & $30.9(12.6)$ \\
\hline
\end{tabular}

${ }^{\mathrm{a}}$ Children whose mothers provided a breast milk sample and have at least one measurement of blood pressure in childhood

non-European background $(<5 \%)$ were similar among studies, but the prevalence of other covariates varied, e.g. smoking during pregnancy varied between 0 and $23.3 \%$ (Table 1 ).

Mean (SD) breast milk DHA level was $0.49(0.28) \mathrm{wt} \%$. The study-specific mean values of breast milk DHA varied from $0.22(0.20)$ to $0.76(0.47) \mathrm{wt} \%$ (Supplementary Table 2). Mean SBP and DBP $z$-scores were $0.49(0.29)$ and 0.86 (1.05), respectively. In general, we observed that children at the lower ages had the highest BP $z$-scores. Studyspecific averages (SD) of SBP and DBP varied from 93.9 (8.4) to 116.0 (9.9) $\mathrm{mmHg}$, and from 50.7 (7.7) to 71.5 (5.6) $\mathrm{mmHg}$, respectively (Online resource 1; Table 2).

For most studies, the estimate for the association between DHA and SBP was below 0, ranging from -0.57 to $-9.65 \mathrm{mmHg}$ lower SBP for each $0.1 \mathrm{wt} \%$ increase in DHA. Confidence intervals of these estimates included 0 for all studies. For DBP, the estimates ranged from -3.09 to $1.94 \mathrm{mmHg}$, with confidence intervals overlapping 0 for all but one study (Table 2). The overall pooled analysis did not show any significant associations as the combined estimate showed that each $0.1 \mathrm{wt} \%$ increase in DHA was associated with a $-1.19(95 \% \mathrm{CI}-3.31,0.94) \mathrm{mmHg}$ lower SBP, and $\mathrm{a}-0.44(95 \% \mathrm{CI}-2.57,1.70) \mathrm{mmHg}$ lower DBP (Table 3;
Fig. 1). Similar results were seen when DHA was dichotomized at the median level of each study (Online resource 1; Supplementary Table 2). There was no association between breast milk DHA and child's height or between breast milk DHA and child's BMI (data not shown). For those studies that had an intervention component in the design of the original study (COPSAC2010, CU Trial, PIAMA), the associations were independent of the intervention arm.

For SBP, the $p$ value for the interaction term for DHA $\times$ age was $<0.10$ in 4 out of 7 studies; for DBP this was 3 out of 7 studies. There was no clear age-related pattern for the association between DHA and BP (Supplementary Table 3 of online resource 1 and illustrated in Fig. 2a, c). The $p$ value for the interaction term for DHA $\times$ sex was $>0.10$ in all studies, but the interaction term for DHA $\times$ age $\times$ sex had a $p$ value $<0.10$ in 1 out of 7 studies for SBP and DBP. In general, the estimates for boys and girls across ages seems to be close from each other at all ages, but tended to diverge for SBP in early life and adolescence, where blood pressure was lower for boys than girls per wt $\%$ increase in breast milk DHA (Fig. 2b, d).

Overall, there were no associations between EPA and the ratio of DHA/AA and BP (systolic or diastolic) 
Table 2 Mean (SD) of breast milk fatty acids and blood pressure for each study participating in the meta-analysis

\begin{tabular}{|c|c|c|c|c|c|c|c|c|}
\hline \multirow[t]{2}{*}{ Acronym } & \multicolumn{3}{|c|}{$\begin{array}{l}\text { Breast milk fatty acids (wt\%); mean } \\
\text { (SD) }\end{array}$} & \multicolumn{5}{|c|}{ Blood pressure; mean (SD) } \\
\hline & DHA & EPA & DHA:AA & Age (years) & $\begin{array}{l}\text { Systolic } \\
(\mathrm{mmHg})\end{array}$ & $\begin{array}{l}\text { Systolic } \\
\text { (z-score) }\end{array}$ & $\begin{array}{l}\text { Diastolic } \\
(\mathrm{mmHg})\end{array}$ & Diastolic (z-score) \\
\hline COPSAC2000 & $0.54(0.29)$ & $0.12(0.08)$ & $0.92(0.44)$ & $\begin{array}{l}12 \\
18\end{array}$ & $\begin{array}{l}111.9(8.8) \\
116.0(9.9)\end{array}$ & $\begin{array}{l}0.40(0.79) \\
0.08(0.86)\end{array}$ & $\begin{array}{l}68.7(5.3) \\
71.5(5.6)\end{array}$ & $\begin{array}{l}0.52(0.52) \\
0.37(0.63)\end{array}$ \\
\hline COPSAC2010 & $0.36(0.19)$ & $0.12(0.07)$ & $1.00(0.46)$ & $\begin{array}{l}3 \\
6 \\
8\end{array}$ & $\begin{array}{l}95.8(6.4) \\
101.4(6.3) \\
103.2(6.0)\end{array}$ & $\begin{array}{l}0.55(0.60) \\
0.64(0.62) \\
0.54(0.61)\end{array}$ & $\begin{array}{l}61.8(4.8) \\
64.1(4.9) \\
65.3(4.4)\end{array}$ & $\begin{array}{l}1.37(0.50) \\
0.80(0.52) \\
0.62(0.46)\end{array}$ \\
\hline CU Trial & $0.76(0.47)$ & $0.19(0.12)$ & $1.60(0.97)$ & $\begin{array}{l}2.5 \\
7 \\
13\end{array}$ & $\begin{array}{l}110.8(10.7) \\
101.9(6.8) \\
107.3(7.3)\end{array}$ & $\begin{array}{l}1.72(0.62) \\
0.53(0.69) \\
1.34(0.74)\end{array}$ & $\begin{array}{l}66.2(9.1) \\
65.6(5.3) \\
62.9(5.7)\end{array}$ & $\begin{array}{l}1.74(0.60) \\
0.77(0.56) \\
0.90(0.90)\end{array}$ \\
\hline EDEN & $0.66(0.22)$ & $0.07(0.05)$ & $0.77(0.24)$ & $\begin{array}{l}3 \\
5\end{array}$ & $\begin{array}{l}93.9(8.4) \\
102.0(7.9)\end{array}$ & $\begin{array}{l}0.34(0.79) \\
0.77(0.75)\end{array}$ & $\begin{array}{l}50.7(7.7) \\
55.6(8.3)\end{array}$ & $\begin{array}{l}0.21(0.78) \\
0.05(0.83)\end{array}$ \\
\hline KOALA & $0.41(0.17)$ & $0.10(0.05)$ & $0.81(0.37)$ & 6 & $105.1(9.6)$ & $1.03(0.85)$ & $60.8(8.1)$ & $0.47(0.81)$ \\
\hline $\mathrm{OCC}$ & $0.29(0.17)$ & $0.10(0.07)$ & $0.82(0.44)$ & $\begin{array}{l}0.4 \\
1.5 \\
3 \\
5\end{array}$ & $\begin{array}{l}101.9(12.6) \\
102.1(8.9) \\
98.2(7.3) \\
101.1(6.5)\end{array}$ & $\begin{array}{l}1.54(1.20) \\
1.28(0.84) \\
0.63(0.69) \\
0.53(0.64)\end{array}$ & $\begin{array}{l}61.6(10.1) \\
63.5(7.6) \\
62.0(5.7) \\
63.7(6.4)\end{array}$ & $\begin{array}{l}2.28(0.89) \\
1.88(0.68) \\
1.20(0.51) \\
0.80(0.57)\end{array}$ \\
\hline PIAMA & $0.22(0.20)$ & $0.06(0.05)$ & $0.59(0.54)$ & $\begin{array}{l}12 \\
16\end{array}$ & $\begin{array}{l}114.5(9.5) \\
114.9(8.7)\end{array}$ & $\begin{array}{l}0.66(0.86) \\
0.18(0.80)\end{array}$ & $\begin{array}{l}66.3(6.5) \\
65.3(6.4)\end{array}$ & $\begin{array}{l}0.31(0.65) \\
-0.23(0.68)\end{array}$ \\
\hline
\end{tabular}

Table 3 Cohort-specific and pooled estimates of the associations between breast milk DHA level and blood pressure

\begin{tabular}{llllll}
\hline & \multicolumn{2}{l}{ Model $1^{\mathrm{a}}$} & & \multicolumn{2}{l}{ Model $2^{\mathrm{b}}$} \\
\cline { 2 - 3 } & SBP $(\mathrm{mmHg})$ & DBP $(\mathrm{mmHg})$ & & SBP $(\mathrm{mmHg})$ & DBP $(\mathrm{mmHg})$ \\
\hline COPSAC2000 & $-1.81(-4.67,1.06)$ & $-1.75(-3.50,-0.003)$ & & $-2.37(-5.28,0.54)$ & $-1.66(-3.45,0.12)$ \\
COPSAC2010 & $1.33(-0.82,3.49)$ & $1.25(-0.38,2.88)$ & & $1.52(-0.72,3.75)$ & $1.51(-0.18,3.20)$ \\
CU Trial & $-1.42(-4.11,1.27)$ & $0.64(-1.16,2.43)$ & & $-0.57(-3.73,2.59)$ & $1.18(-0.92,3.28)$ \\
EDEN & $-2.17(-4.40,0.06)$ & $-3.06(-5.32,-0.80)$ & & $-1.64(-4.02,0.73)$ & $-3.09(-5.48,-0.71)$ \\
KOALA & $-3.83(-17.1,9.45)$ & $3.92(-7.03,14.9)$ & & $-9.65(-24.3,5.04)$ & $-3.03(-14.78,8.71)$ \\
OCC & $-2.84(-7.27,1.59)$ & $-2.01(-5.61,1.58)$ & & $-3.14(-8.23,1.95)$ & $-1.52(-5.86,2.82)$ \\
PIAMA & $-4.26(-11.39,2.87)$ & $3.03(-2.05,8.11)$ & & $-5.40(-13.91,3.11)$ & $1.94(-3.99,7.87)$ \\
Pooled & $-1.29(-3.21,0.62)$ & $-0.42(-2.45,1.60)$ & & $-1.19(-3.31,0.94)$ & $-0.44(-2.57,1.70)$ \\
\hline
\end{tabular}

Values are regression coefficients expressed in $\mathrm{mmHg}$ for each $0.1 \mathrm{wt} \%$ increase in DHA level

$D B P$ diastolic blood pressure, $S B P$ systolic blood pressure

${ }^{a}$ Adjusted for height, sex, and age

${ }^{\mathrm{b}}$ Model $1+$ maternal smoking, maternal educational level, maternal age, maternal BMI (not for COPSAC2000/COPSAC2010), gestational age, child's birth weight, maternal place of birth (not for CU Trial), and breastfeeding duration

(Supplementary Tables 4 and 5 of online resource 1, respectively).

\section{Discussion}

\section{Summary of main findings}

This individual participant meta-analysis of seven studies representing 2188 children with BP assessment in the full range from infancy to adolescence, observed no overall association between systolic or DBP and increasing levels of breast milk DHA ranging from mean of 0.22-0.76 wt\%. There were also no associations between BP and increasing levels of EPA or of DHA/AA ratio in breast milk, and no signs of age or sex differences in the associations.

\section{Comparison with earlier studies and implications}

Our result is in line with four earlier publications that reported no association between early life n-3 LC PUFAs intake and BP in childhood [17, 19, 21, 23], with an age at 
Fig. 1 a Cohort-specific and pooled mean difference $(95 \%$ CI) in systolic blood pressure $(\mathrm{mmHg})$ per $0.1 \mathrm{wt} \%$ increase in breast milk DHA levels (two-stage meta-analysis). Figure represents numbers of Table 2, model 2. Overall estimate: $-1.19 \mathrm{mmHg}(95 \% \mathrm{CI}$ $-3.31,0.94), Q=3.45, d f=6$, $I^{2}=0 \%$. b Cohort-specific and pooled mean difference ( $95 \%$

CI) in diastolic blood pressure $(\mathrm{mmHg})$ per $0.1 \mathrm{wt} \%$ increase in breastmilk DHA levels (twostage meta-analysis). Figure represents numbers of Table 2, model 2. Overall estimate:

$-0.44 \mathrm{mmHg}(95 \% \mathrm{CI}-2.57$, 1.70), $Q=4.51, d f=6, I^{2}=0 \%$
A

Association between DHA and Systolic Blood Pressure $(\mathrm{mmHg})$ Difference and $95 \% \mathrm{CL}$

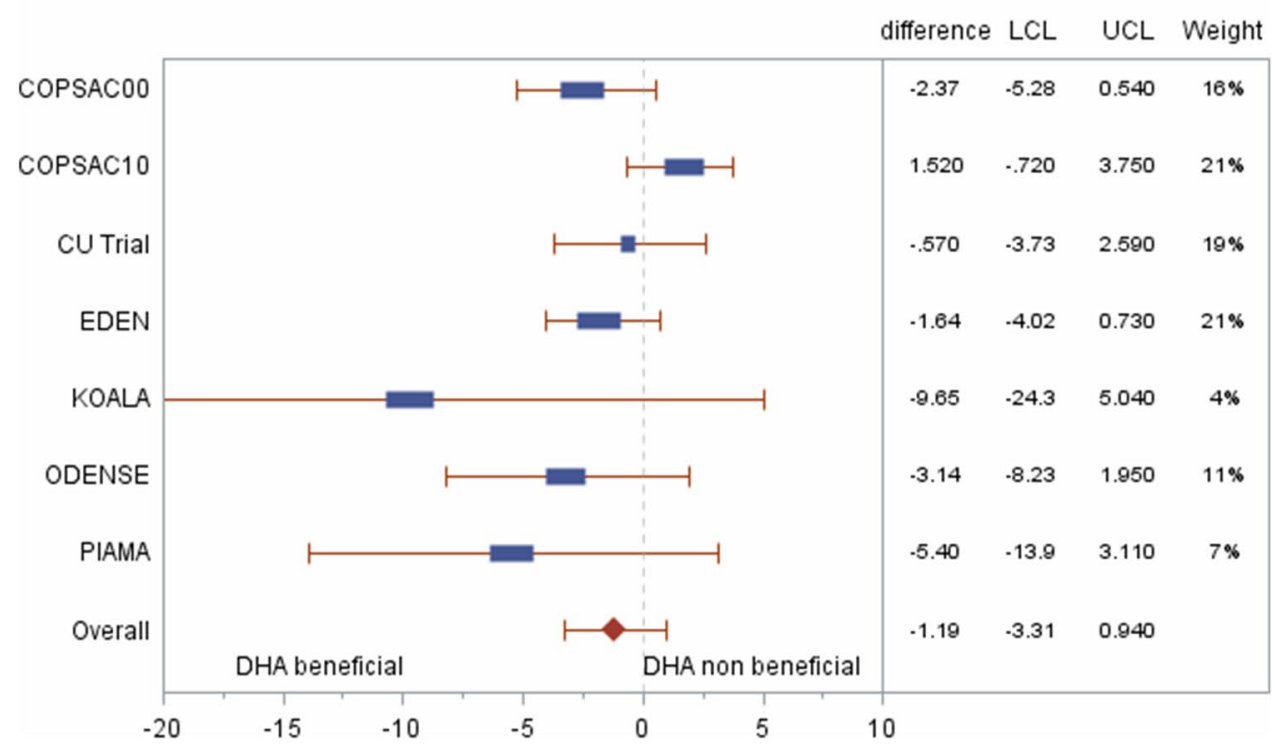

B

Association between DHA and Diastolic Blood Pressure ( $\mathrm{mmHg}$ ) Difference and $95 \% \mathrm{CL}$

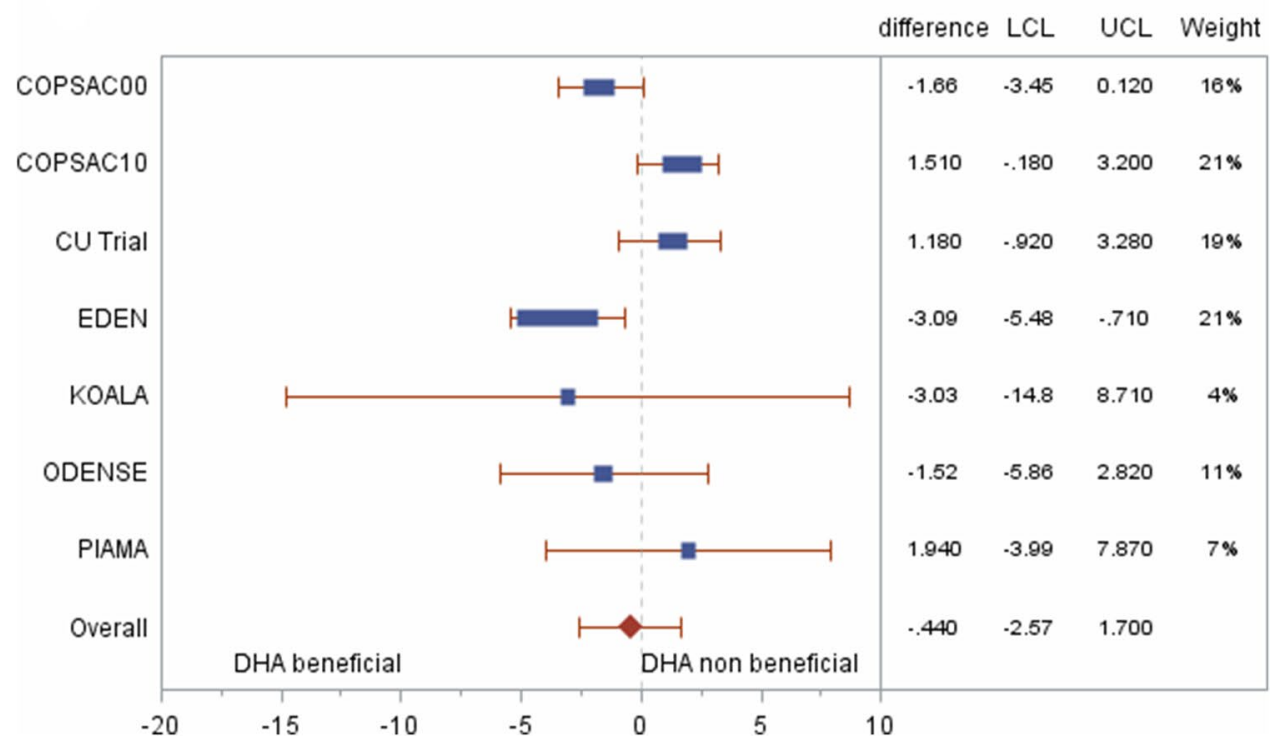

outcome measurement ranging from 2.5 to 9 years. These studies directly supplemented infants $(280 \mathrm{mg} /$ day DHA as ethyl-ester form from birth to 6 months) [19] or infant formula with n-3 LC PUFA (0.30 wt\% DHA as triglyceride and phospholipid forms from birth to 2 months) [17], and one of the studies [21, 23] supplemented lactating mothers with fish oil. Conversely, two other studies reported that n-3 LC PUFAs were associated with a lower BP [16, 18]. One of which was a multicentric European RCT that supplemented infant formula with $0.15-0.25 \mathrm{wt} \%$ of DHA (as egg phospholipid form) found a lower BP in 6-year-old children $(-3.6 \mathrm{mmHg}$ for DBP; not significant for SBP)
[18]. The second one was our previous observational study, where we found that children who received breast milk with a DHA $\geq 0.18 \mathrm{wt} \%$ had a lower BP $(-4.79 \mathrm{mmHg}$ for SBP and $-2.47 \mathrm{mmHg}$ for SBP) at the age of 12 compared to children who received infant formula with no DHA (with adjustment for child's sex) [16]. Another report found a lower BP with higher mother's milk n-3 LCPUFAs (ranging $0.24-0.47 \mathrm{wt} \%$, with $75 \%$ being DHA) but only in boys (SBP and DBP) at 4 months of age, then only in girls (SBP) at 18 months of age, and no association regardless the infant sex at 36 months of age [43]. One study found a higher BP in boys whose mothers were supplemented with fish oil 

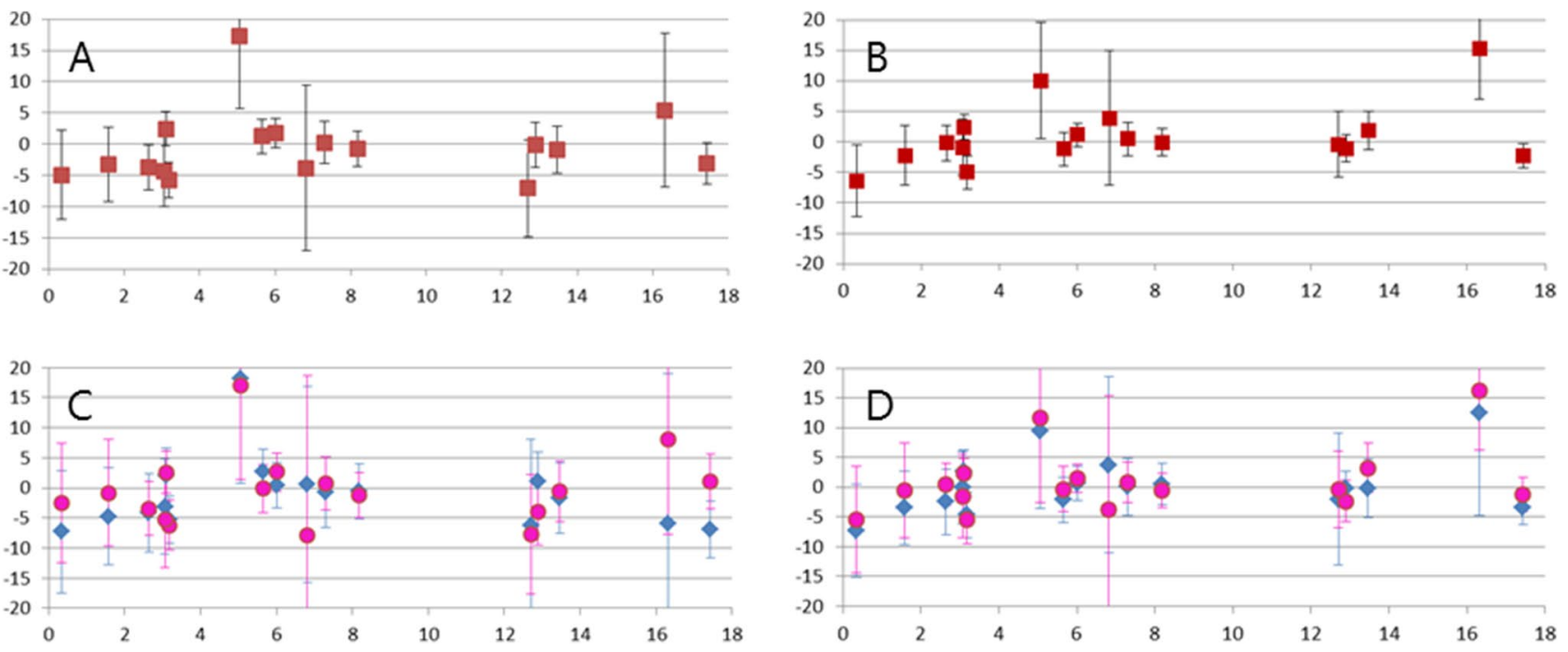

Fig. 2 Difference in systolic (a, c) and diastolic (b, d) blood pressure ( $\mathrm{mmHg}$ ) per $0.1 \mathrm{wt} \%$ increase in breastmilk DHA levels, displayed for increasing age (years), and stratified by sex (c, $\mathbf{d}$; pink bullets are girls, blue diamonds are boys)

during lactation at the age of 7 years [20], with replication of the findings at the age of 13 [22]. Our meta-analysis did not show clear sex differences for the association between DHA and BP, though the associations seemed to be more beneficial for boys, especially in early age and adolescence. The differences in the associations between n-3 LC PUFA and $\mathrm{BP}$ in the earlier studies cited herein does not seem to be related to study design, age at BP assessment, method of administration, or level of n-3 LC PUFA. This meta-analysis adds to the literature by including data from several unpublished studies with data on breast milk DHA, and by harmonizing the data to enhance comparability. Relevant issues to consider in future studies are potential interference from other components in infant feeding or lifestyle factors, the latter being important to study in the context of an RCT design.

\section{Methodological considerations}

The strength of our study is that we included all eligible studies, irrespective of whether these studies had published the results. Moreover, most studies did not have the association of interest in this paper as a primary research question, which prevented publication bias [44]. Also, the studies included in the meta-analysis had a wide range of breast milk DHA, and our associations represent increments that can be expected by supplementing women with the recommended dose of DHA [45, 46]. However, our study has some limitations that should be taken into account when interpreting the results. First, all cohorts had loss-to-follow-up in the period between breast milk collection and BP measurements. This could have led to selection bias if those with a low or high DHA level and a low or high BP were selectively lost to follow up. Second, when converting the BPs to $z$-scores by the percentiles of "The Fourth Report on the Diagnosis, Evaluation, and Treatment of High BP in Children and Adolescents", we noticed relatively high BP $z$-scores in all studies included in this meta-analysis, but especially in younger children. This is possibly related to the method of measurements (e.g. number of repeats) as well as the difficulty of measuring BP in young children. Although this would not have affected validity, associations between DHA and BP could be less precise in younger children. Indeed, absolute BPs were comparable with an earlier study investigating the association between DHA and BP in children, but SEs were smaller in this study, and statistically significant associations were detected [42]. Third, most studies used a single sample of breast milk to determine the amount of breast milk $n-3$ LCPUFAs, which may have led to misclassification of the exposure as breastmilk n-3 LCPUFA vary from day to day based on the mothers recent intake of fish [47]. Thus, the latter two limitations may have prevented us to find a real association between n-3 LC PUFAs and BP, if present.

\section{Clinical relevance}

The results reported in our study are per $0.1 \mathrm{wt} \%$ increase in breast milk fatty acids, which is a relatively small increase, and results in a small potential change in BP which is not clinically relevant. Though statistical significance and precision remains unchanged, we illustrate implications for clinical relevant changes in BP if breast milk DHA increases to a larger, but feasible, extent. Per SD increase in DHA, DHA is associated with a $3.24 \mathrm{mmHg}$ lower $(95 \% \mathrm{CI}-8.59$, 
2.10) SBP, and a $1.11 \mathrm{mmHg}$ lower $(95 \% \mathrm{CI}-5.68,3.46)$ DBP. If breast milk DHA increases with $0.8 \mathrm{wt} \%$ (which is the increase that was measured after supplementing women with fish oil during lactation), DHA is associated with a $9.52 \mathrm{mmHg}$ lower $(95 \% \mathrm{CI}-26.51,7.47) \mathrm{SBP}$, and a $3.50 \mathrm{mmHg}$ lower $(95 \% \mathrm{CI}-20.59,13.58)$ DBP.

\section{Implications}

Although hypertension is rare in childhood [48], BP tends to track from childhood to adulthood from a very young age [49]. Therefore, the less increased the BP in childhood, the lower the risk of hypertension in adulthood, which implies that prevention of hypertension should start early in life. Our results do not support a beneficial effect of breast milk n-3 LC PUFAs on childhood BP. However, the current global recommendations for pregnant and lactating women of $200 \mathrm{mg} /$ day of DHA intake (obtained for example by one portion of oily fish a week) still apply for other health outcomes [50].

\section{Conclusion}

This meta-analysis does not support an association between breast milk n-3 LC PUFAs and BP throughout childhood in boys or girls.

Acknowledgements This study was funded by the Netherlands Heart Foundation (Grant no. 2013T025).

\section{Compliance with ethical standards}

Ethical approval All procedures performed in studies involving human participants were in accordance with the ethical standards of the institutional and/or national research committees and with the 1964 Helsinki Declaration and its later amendments or comparable ethical standards.

Conflict of interest The authors declare that they have no conflict of interest.

Open Access This article is licensed under a Creative Commons Attribution 4.0 International License, which permits use, sharing, adaptation, distribution and reproduction in any medium or format, as long as you give appropriate credit to the original author(s) and the source, provide a link to the Creative Commons licence, and indicate if changes were made. The images or other third party material in this article are included in the article's Creative Commons licence, unless indicated otherwise in a credit line to the material. If material is not included in the article's Creative Commons licence and your intended use is not permitted by statutory regulation or exceeds the permitted use, you will need to obtain permission directly from the copyright holder. To view a copy of this licence, visit http://creativecommons.org/licenses/by/4.0/.

\section{References}

1. Victora CG, Bahl R, Barros AJ, Franca GV, Horton S, Krasevec J, Murch S, Sankar MJ, Walker N, Rollins NC (2016) Breastfeeding in the 21st century: epidemiology, mechanisms, and lifelong effect. Lancet 387(10017):475-490. https://doi.org/10.1016/ S0140-6736(15)01024-7

2. Horta BL, de Loret MC, Victora CG (2015) Long-term consequences of breastfeeding on cholesterol, obesity, systolic blood pressure and type 2 diabetes: a systematic review and metaanalysis. Acta Paediatr 104(467):30-37. https://doi.org/10.1111/ apa.13133

3. Martin RM, Gunnell D, Smith GD (2005) Breastfeeding in infancy and blood pressure in later life: systematic review and meta-analysis. Am J Epidemiol 161(1):15-26. https://doi.org/10.1093/aje/ kwh338

4. Owen CG, Whincup PH, Gilg JA, Cook DG (2003) Effect of breast feeding in infancy on blood pressure in later life: systematic review and meta-analysis. BMJ 327(7425):1189-1195. https ://doi.org/10.1136/bmj.327.7425.1189

5. Andreas NJ, Kampmann B, Mehring Le-Doare K (2015) Human breast milk: A review on its composition and bioactivity. Early Hum Dev 91(11):629-635. https://doi.org/10.1016/j.earlhumdev .2015 .08 .013

6. Calder PC (2016) Docosahexaenoic Acid. Ann Nutr Metab 69(Suppl 1):7-21. https://doi.org/10.1159/000448262

7. Cicero AF, Ertek S, Borghi C (2009) Omega-3 polyunsaturated fatty acids: their potential role in blood pressure prevention and management. Curr Vasc Pharmacol 7(3):330-337

8. Mori TA, Bao DQ, Burke V, Puddey IB, Beilin LJ (1999) Docosahexaenoic acid but not eicosapentaenoic acid lowers ambulatory blood pressure and heart rate in humans. Hypertension 34(2):253260. https://doi.org/10.1161/01.hyp.34.2.253

9. Limbu R, Cottrell GS, McNeish AJ (2018) Characterisation of the vasodilation effects of DHA and EPA, n-3 PUFAs (fish oils), in rat aorta and mesenteric resistance arteries. PLoS ONE 13(2):e0192484. https://doi.org/10.1371/journal.pone.0192484

10. Hanson MA, Gluckman PD (2014) Early developmental conditioning of later health and disease: physiology or pathophysiology? Physiol Rev 94(4):1027-1076. https://doi.org/10.1152/physr ev.00029.2013

11. Armitage JA, Pearce AD, Sinclair AJ, Vingrys AJ, Weisinger RS, Weisinger HS (2003) Increased blood pressure later in life may be associated with perinatal n-3 fatty acid deficiency. Lipids 38(4):459-464

12. Fu Y, Liu X, Zhou B, Jiang AC, Chai L (2016) An updated review of worldwide levels of docosahexaenoic and arachidonic acid in human breast milk by region. Public Health Nutr 19(15):26752687. https://doi.org/10.1017/S1368980016000707

13. Armand M, Bernard JY, Forhan A, Heude B, Charles MA (2018) Maternal nutritional determinants of colostrum fatty acids in the EDEN mother-child cohort. Clin Nutr 37(6 Pt A):2127-2136. https://doi.org/10.1016/j.clnu.2017.10.007

14. Innis SM (2007) Human milk: maternal dietary lipids and infant development. Proc Nutr Soc 66(3):397-404. https://doi. org/10.1017/S0029665107005666

15. Molto-Puigmarti C, Plat J, Mensink RP, Muller A, Jansen E, Zeegers MP, Thijs C (2010) FADS1 FADS2 gene variants modify the association between fish intake and the docosahexaenoic acid proportions in human milk. Am J Clin Nutr 91(5):1368-1376. https://doi.org/10.3945/ajen.2009.28789

16. Van Rossem L, Wijga AH, de Jongste JC, Koppelman GH, Oldenwening M, Postma DS, Abrahamse-Berkeveld M, van de Heijning B, Brunekreef B, SmitHA (2012) Blood pressure in 12-yearold children is associated with fatty acid composition of human 
milk: the prevention and incidence of asthma and miteallergy birth cohort. Hypertension 60(4):1055-1060. https://doi.org/10.1161/ HYPERTENSIONAHA.112.197830

17. De Jong C, Boehm G, Kikkert HK, Hadders-Algra M (2011) The Groningen LCPUFA study: no effect of short-term postnatal longchain polyunsaturated fatty acids in healthy term infants on cardiovascular and anthropometric development at 9 years. Pediatr Res 70(4):411-416. https://doi.org/10.1203/PDR.0b013e31822a5ee0

18. Forsyth JS, Willatts P, Agostoni C, Bissenden J, Casaer P, Boehm G (2003) Long chain polyunsaturated fatty acid supplementation in infant formula and blood pressure in later childhood: follow up of a randomised controlled trial. BMJ 326(7396):953. https://doi. org/10.1136/bmj.326.7396.953

19. See VHL, Mori TA, Prescott SL, Beilin LJ, Burrows S, Huang $\mathrm{RC}$ (2018) Cardiometabolic risk factors at 5 years after omega- 3 fatty acid supplementation in infancy. Pediatrics. https://doi. org/10.1542/peds.2016-2623

20. Asserhoj M, Nehammer S, Matthiessen J, Michaelsen KF, Lauritzen L (2009) Maternal fish oil supplementation during lactation may adversely affect long-term blood pressure, energy intake, and physical activity of 7-year-old boys. J Nutr 139(2):298-304. https ://doi.org/10.3945/jn.108.095745

21. Larnkjaer A, Christensen JH, Michaelsen KF, Lauritzen L (2006) Maternal fish oil supplementation during lactation does not affect blood pressure, pulse wave velocity, or heart rate variability in 2.5y-old children. J Nutr 136(6):1539-1544. https://doi.org/10.1093/ jn/136.6.1539

22. Lauritzen L, Eriksen SE, Hjorth MF, Nielsen MS, Olsen SF, Stark KD, Michaelsen KF, Damsgaard CT (2016) Maternal fish oil supplementation during lactation is associated with reduced height at 13 years of age and higher blood pressure in boys only. Br J Nutr 116(12):2082-2090. https://doi.org/10.1017/S00071145160042 93

23. Ulbak J, Lauritzen L, Hansen HS, Michaelsen KF (2004) Diet and blood pressure in 2.5-y-old Danish children. Am J Clin Nutr 79(6):1095-1102. https://doi.org/10.1093/ajcn/79.6.1095

24. Innes JK, Calder PC (2018) The differential effects of eicosapentaenoic acid and docosahexaenoic acid on cardiometabolic risk factors: a systematic review. Int J Mol Sci. https://doi.org/10.3390/ ijms 19020532

25. Kelley DS, Adkins Y (2012) Similarities and differences between the effects of EPA and DHA on markers of atherosclerosis in human subjects. Proc Nutr Soc 71(2):322-331. https://doi. org/10.1017/S0029665112000080

26. Bisgaard H (2004) The Copenhagen Prospective Study on Asthma in Childhood (COPSAC): design, rationale, and baseline data from a longitudinal birth cohort study. Ann Allergy Asthma Immunol 93(4):381-389. https://doi.org/10.1016/S1081-1206(10)61398-1

27. Bisgaard H, Vissing NH, Carson CG, Bischoff AL, Folsgaard NV, Kreiner-Moller E, Chawes BL, Stokholm J, Pedersen L, Bjarnadottir E, Thysen AH, Nilsson E, Mortensen LJ, Olsen SF, Schjorring S, Krogfelt KA, Lauritzen L, Brix S, Bonnelykke K (2013) Deep phenotyping of the unselected COPSAC2010 birth cohort study. Clin Exp Allergy 43(12):1384-1394. https://doi. org/10.1111/cea.12213

28. Heude B, Forhan A, Slama R, Douhaud L, Bedel S, SaurelCubizolles MJ, Hankard R, Thiebaugeorges O, De AM, AnnesiMaesano I, Kaminski M, Charles MA (2016) Cohort profile: the EDEN mother-child cohort on the prenatal and early postnatal determinants of child health and development. Int J Epidemiol 45(2):353-363. https://doi.org/10.1093/ije/dyv151

29. Kummeling I, Thijs C, Penders J, Snijders BE, Stelma F, Reimerink J, Koopmans M, Dagnelie PC, Huber M, Jansen MC, de BR, van den Brandt PA (2005) Etiology of atopy in infancy: the KOALA Birth Cohort Study. Pediatr Allergy Immunol 16(8):679684. https://doi.org/10.1111/j.1399-3038.2005.00333.x
30. Kyhl HB, Jensen TK, Barington T, Buhl S, Norberg LA, Jorgensen JS, Jensen DF, Christesen HT, Lamont RF, Husby S (2015) The Odense Child Cohort: aims, design, and cohort profile. Paediatr Perinat Epidemiol 29(3):250-258. https://doi.org/10.1111/ ppe. 12183

31. Wijga AH, Kerkhof M, Gehring U, de Jongste JC, Postma DS, Aalberse RC, Wolse AP, Koppelman GH, van RL, Oldenwening M, Brunekreef B, Smit HA (2014) Cohort profile: the prevention and incidence of asthma and mite allergy (PIAMA) birth cohort. Int J Epidemiol 43(2):527-535. https://doi.org/10.1093/ije/dys23 1

32. Lauritzen L, Jorgensen MH, Mikkelsen TB, Skovgaard L, Straarup EM, Olsen SF, Hoy CE, Michaelsen KF (2004) Maternal fish oil supplementation in lactation: effect on visual acuity and n-3 fatty acid content of infant erythrocytes. Lipids 39(3):195-206

33. Rodriguez MA, Petrini J, Ferreira EM, Mourao LR, Salvian M, Cassoli LD, Pires AV, Machado PF, Mourao GB (2014) Concordance analysis between estimation methods of milk fatty acid content. Food Chem 156:170-175. https://doi.org/10.1016/j.foodc hem.2014.01.092

34. Liu Z, Ezernieks V, Rochfort S, Cocks B (2018) Comparison of methylation methods for fatty acid analysis of milk fat. Food Chem 261:210-215. https://doi.org/10.1016/j.foodchem.2018.04.053

35. Brenna JT, Plourde M, Stark KD, Jones PJ, Lin YH (2018) Best practices for the design, laboratory analysis, and reporting of trials involving fatty acids. Am J Clin Nutr 108(2):211-227. https://doi. org/10.1093/ajen/nqy089

36. Flynn JT, Falkner BE (2017) New clinical practice guideline for the management of high blood pressure in children and adolescents. Hypertension 70(4):683-686. https://doi.org/10.1161/ HYPERTENSIONAHA.117.10050

37. Higgins JP (2008) Commentary: heterogeneity in meta-analysis should be expected and appropriately quantified. Int J Epidemiol 37(5):1158-1160. https://doi.org/10.1093/ije/dyn204

38. Riley RD, Lambert PC, Abo-Zaid G (2010) Meta-analysis of individual participant data: rationale, conduct, and reporting. BMJ 340:c221. https://doi.org/10.1136/bmj.c221

39. Colussi G, Catena C, Novello M, Bertin N, Sechi LA (2017) Impact of omega- 3 polyunsaturated fatty acids on vascular function and blood pressure: Relevance for cardiovascular outcomes. Nutr Metab Cardiovasc Dis 27(3):191-200. https://doi. org/10.1016/j.numecd.2016.07.011

40. Al-Hinai M, Baylin A, Tellez-Rojo MM, Cantoral A, Ettinger A, Solano-Gonzalez M, Peterson KE, Perng W (2018) Maternal intake of omega- 3 and omega- 6 polyunsaturated fatty acids during mid-pregnancy is inversely associated with linear growth. J Dev Orig Health Dis 9(4):432-441. https://doi.org/10.1017/S2040 174418000193

41. Stratakis N, Roumeliotaki T, Oken E, Barros H, Basterrechea M, Charles MA, Eggesbo M, Forastiere F, Gaillard R, Gehring U, Govarts E, Hanke W, Heude B, Iszatt N, Jaddoe VW, Kelleher C, Mommers M, Murcia M, Oliveira A, Pizzi C, Polanska K, Porta D, Richiardi L, Rifas-Shiman SL, Schoeters G, Sunyer J, Thijs C, Viljoen K, Vrijheid M, Vrijkotte TG, Wijga AH, Zeegers MP, Kogevinas M, Chatzi L (2016) Fish Intake in pregnancy and child growth: a pooled analysis of 15 European and US birth cohorts. JAMA Pediatr 170(4):381-390. https://doi.org/10.1001/jamap ediatrics.2015.4430

42. Kerling EH, Hilton JM, Thodosoff JM, Wick J, Colombo J, Carlson SE (2019) Effect of prenatal docosahexaenoic acid supplementation on blood pressure in children with overweight condition or obesity: a secondary analysis of a randomized clinical trial. JAMA Netw Open 2(2):e190088. https://doi.org/10.1001/jaman etworkopen.2019.0088

43. Bruun S, van RL, Lauritzen L, Husby S, Neergaard JL, Michaelsen KF, Boysen SM, Stark KD, Sorensen J, Zachariassen G (2019) 
Content of n-3 LC-PUFA in breast milk four months postpartum is associated with infancy blood pressure in boys and infancy blood lipid profile in girls. Nutrients. https://doi.org/10.3390/nu110 20235

44. Ahmed I, Sutton AJ, Riley RD (2012) Assessment of publication bias, selection bias, and unavailable data in meta-analyses using individual participant data: a database survey. BMJ 344:d7762. https://doi.org/10.1136/bmj.d7762

45. Sherry CL, Oliver JS, Marriage BJ (2015) Docosahexaenoic acid supplementation in lactating women increases breast milk and plasma docosahexaenoic acid concentrations and alters infant omega 6:3 fatty acid ratio. Prostaglandins Leukot Essent Fatty Acids 95:63-69. https://doi.org/10.1016/j.plefa.2015.01.005

46. Van Goor SA, Dijck-Brouwer DA, Hadders-Algra M, Doornbos B, Erwich JJ, Schaafsma A, Muskiet FA (2009) Human milk arachidonic acid and docosahexaenoic acid contents increase following supplementation during pregnancy and lactation. Prostaglandins Leukot Essent Fatty Acids 80(1):65-69. https://doi.org/10.1016/j. plefa.2008.11.002

47. Jorgensen MH, Hernell O, Hughes E, Michaelsen KF (2001) Is there a relation between docosahexaenoic acid concentration in mothers' milk and visual development in term infants? J Pediatr Gastroenterol Nutr 32(3):293-296. https://doi.org/10.1097/00005 176-200103000-00011

48. Rao G (2016) Diagnosis, epidemiology, and management of hypertension in children. Pediatrics. https://doi.org/10.1542/ peds.2015-3616

49. Chen X, Wang Y (2008) Tracking of blood pressure from childhood to adulthood: a systematic review and meta-regression analysis. Circulation 117(25):3171-3180. https://doi.org/10.1161/ CIRCULATIONAHA.107.730366

50. Koletzko B, Lien E, Agostoni C, Bohles H, Campoy C, Cetin I, Decsi T, Dudenhausen JW, Dupont C, Forsyth S, Hoesli I, Holzgreve W, Lapillonne A, Putet G, Secher NJ, Symonds M, Szajewska H, Willatts P, Uauy R, World Association of Perinatal Medicine Dietary Guidelines Working G (2008) The roles of long-chain polyunsaturated fatty acids in pregnancy, lactation and infancy: review of current knowledge and consensus recommendations. J Perinat Med 36(1):5-14. https://doi.org/10.1515/ JPM.2008.001 